\title{
Democracia e historia en las Antillas de habla inglesa
}

\author{
Juan Manuel de la Serna $H$. \\ CCYDEL-UNAM
}

$\mathrm{E}$

1 mundo se encuentra actualmente en un proceso de cam. bio que es fácilmente percep. tible desde la óptica de las ciencias sociales. La única diferencia existente entre las disciplinas es el nombre que se le asigna a un fenómeno común: el cambio. La economía lo designa como una "redefinición de la división internacional del trabajo" en virtud de la globalización. Esta misma ciencia otorga nombres específicos a pro. cesos que forman parte del mismo fenómeno. En este sentido, en las relaciones internacionales se habla del proceso de globalización o "nuevo orden internacional". La ciencia política percibe dicho proceso como la quie. bra de las democracias, en la que se presenta también una redefinición del espacio político global. A ello deberíamos agregar el resurgimiento $y$ redefinición de las ideologías.

Los procesos de cambio actuales -cuyos ritmos son diversos en los diferentes campos (en esta percepción, la cultura, entendida desde una perspectiva amplia, resulta ser el ámbito que se transforma más lentamente)-1 están condicionados por procesos de transición que anteceden y determinan a las estructuras posteriores. Por esta razón es erróneo limitarse al análisis coyuntural y obviar el estudio de transiciones previas.

Con el objeto de elaborar este ensayo, se identificaron situaciones que

1 Hume, Govermment, 1923, p. 56. 
caracterizan la evolución de las instituciones democráticas en el Caribe angloparlante, tomando en cuenta aquellos momentos históricos que influyeron en la conformación de un sistema que permite caracterizar a la subregión como una de las de mayor estabilidad política, a la vez que presenta una relativa homogeneidad social que puede verse reflejada en sus instituciones públicas.

\section{LA IMPORTANCIA DE LAS INSTTTUCIONES MUNICIPALES}

La institución municipal (o lo que en Hispanoamérica se conoce como tal) fue lo que sirvió de base a las instituciones democráticas del Caribe colo- nial británico. La temprana ocupación inglesa de Jamaica y Barbados (1600, 1650) permitió el trasplante de instituciones jurídico-políticas y de administración más o menos puras; en cambio, en otras islas de ocupación tardía, como Guyana y Trinidad, los cuáqueros ingleses heredaron poderosas instituciones municipales fundadas por holandeses o españoles. Éstas pronto fueron desplazadas por formas de organización de tipo inglés, a pesar de que se produjo en ocasiones una especie de "mestizaje jurídico" entre las antiguas y nuevas instituciones. En Trinidad, por ejemplo, los plantadores ingleses adoptaron el cabildo no sólo por tradición, sino porque esperaban cierta protección ante los oficiales reales de este tipo de gobierno local, al

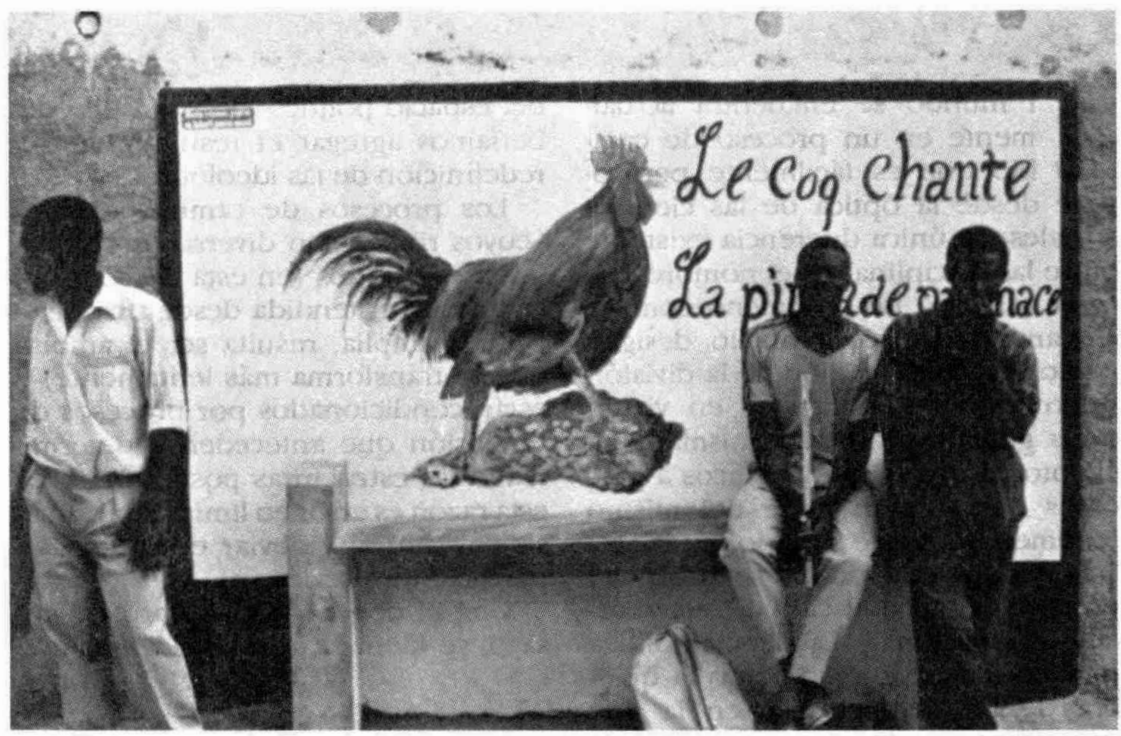


mismotiempo que buscaron en él una garantía para su asentamiento como casta local privilegiada entre los inmigrantes recientes, los esclavos y los pocos indios arwaks sobrevivientes.

Por la peculiaridad de su integración al sistema mundial, la práctica de la vida democrática antillana se inclinó hacia las municipalidades urbanas, que se convirtieron en escenario de enfrentamientos entre representantes de las diferentes facciones políticas y de propietarios, mientras que la vida política de los gobiernos rurales permanecía casi sin vida. Esto fue cierto hasta el momento en que el triunfo del laissez-faire y la abolición de la esclavitud, en el segundo tercio del siglo XIX, modificaron los intereses de las potencias metropolitanas alterando con ello los mecanismos de dominación jurídico-política.

Al comenzar la segunda mitad del siglo $\mathrm{XIX}$, los gobiernos locales antillanos enfrentaron una suerte de oscurantismo, de tal manera que

con un puñado de oligarcas blancos, un reducido número de demagogos de color y un amplio grupo de negros cayó en un estado de total inercia política. $^{2}$

Cualquier forma de gobierno representativo en esta época no podía ser otra cosa que una mera incongruencia. El interés primordial era asegurar el dominio de los británicos blancos sobre el de otras nacionalidades europeas radicadas en las colonias y, por

2 Singh, Local, 1972, p. 26. supuesto,sobre la mayoría de los negros recién liberados.

Los gobiernos coloniales locales, dificiles de caracterizar en un inicio, se transformaron inclinándose hacia un sistema lógico que culminó institucionalmente con la promulgación de las Actas de 1888 y 1894, las cuales, por su importancia, conocieron una amplísima divulgación. Dicho proceso comenzó con la simplificación al definir áreas de competencia y de autoridades para continuar con la implantación efectiva de la legislación y de las tarifas públicas y, finalmente, con el establecimiento de una administración uniforme en todas las colonias antillanas. A partir de entonces el principio de la democracia representativa se convirtió en axioma de la política, aunque el acceso al voto fue gradual y mantuvo su carácter restrictivo: en 1832 los sectores medios obtuvieron el derecho de voto, en 1867 los trabajadores urbanos y en 1884 los rurales. El dominio colonial llegó en ese momento a una etapa de madurez, preparándose para cumplir con las exigencias de la época. ${ }^{3}$

Fuera de las municipalidades urbanas, las rurales estaban divididas en distritos que contaban con una sola autoridad electa y responsable de toda clase de asuntos de administración local. El campesino, lejos de las influencias de la ciudad y de los cambios que se produjeron en ella, permaneció pasivo y al margen del gobierno de la comunidad.

La transición de un gobierno colonial oligárquico a uno democrático llegó a las Antillas pacíficamente des-

3 Day, Five, p. 156. 
pués de la segunda guerra mundial. La restricción del voto a la propiedad fue reemplazada por el sufragio universal de los adultos como base para las elecciones locales.

En Jamaica y Trinidad el sufragio universal para adultos se adoptó de manera simultánea, tanto para las elec. ciones locales como para las nacionales. En cambio, en Barbados y Guyana, y contrariamente a la presunción de la Comisión Real para las Indias Occidentales (Comisión Moyne de 1938) y de la Oficina Colonial, el proceso de sincronización político-electoral entre gobierno local y desarrollo constitucional abrió camino a la creación de instituciones de gobierno.

Contrario al espíritu contestatario de las manifestaciones populares de los años treinta en las Antillas o al rechazo originado por el impacto de la revolución industrial, la democratización política interna o de los consejos locales fue el producto de presiones provenientes de la tradición liberal británica de tiempos remotos (tal vez rastreable hasta el siglo XVII). A las clases propietarias les correspondió jugar un papel similar ya que siempre se mostraron reticentes a renunciar a su posición privilegiada. Después de todo, las Antillas pueden ser consideradas como sociedades preindustriales (con la excepción relativa de ciertas subeconomías petroleras y de la bauxita) en términos de desarrollo económico, por lo que su opinión pública ha crecido históricamente fuera de las estructuras convencionales de las modernas sociedades capitalistas. A ello habría que añadir el estatus colonial que también define las convicciones políticas.

\section{Política Nacional y gobierno} LOCAL. EN LOS NUEVOS ESTADOS

Para estudiar la integración de las sociedades antillanas al capitalismo mundial es necesario tener en cuenta sus características territoriales, étnicas y sociales. Predominan en ellas pequeñas comunidades en las que una miriada de lazos de parentesco, amistad, vecindad y membresías unen a todos en una compleja red de obligaciones mutuas.

Los rangos sociales son escasos (de lo que la música popular es un buen ejemplo, así como los comentarios mordaces de los que a menudo el gobernador en turno era objeto), pero ello no quiere decir que desaparecieran del todo. Un observador británico escribió en 1852: "Casi por obligación las Antillas se han vuelto sumamente democráticas." El comentario debe tomarse más en un sentido social que político, es decir, más en el sentido en que utilizaba Tocqueville el concepto de democracia. Parece válida la afirmación de que en las Antillas la democracia social antecede a la democracia política y existe cierto consenso social aunque no cesa del todo esa especie de guerra subterránea, producto de prejuicios de color, típicos de estas sociedades.

\section{LA CONSTTTUCIÓN EN LA POSGUERRA}

Los estados independientes que surgieron en las Antillas británicas en el transcurso de los años sesenta, se conformaron en calidad de estados democrático-liberales. Una independen- 


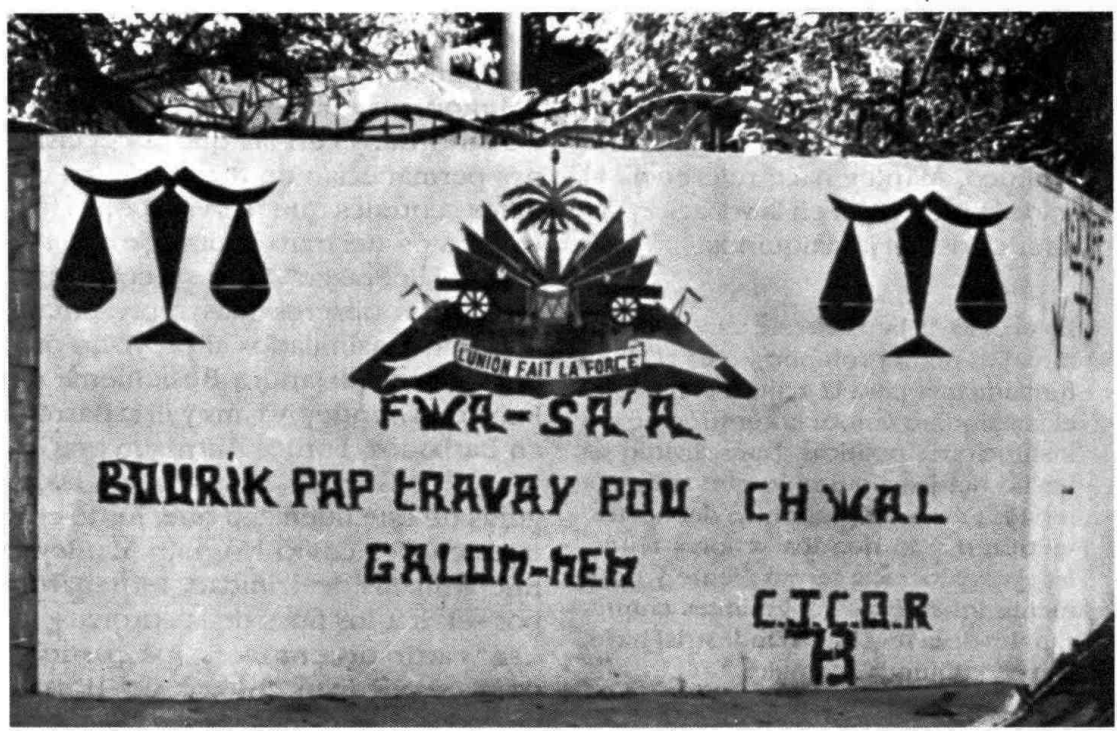

cia negociada (caracterizada por el sociólogo jamaiquino Trevor Monroe como una "descolonización constitucional") les dio origen pero, al mismo tiempo, marcó el inicio de un nuevo vínculo de dependencia.

En esta nueva etapa, el sistema político se basa en la Constitución de Westminster con su sistema electoral depurado, la presencia de los partidos de gobierno y la oposicion en las cámaras. ${ }^{4}$ Es importante resca-

4 "La idea de la democracia parlamentaria basada en el modelo de Westminster que se funda en la idea del conflicto contenido entre grupos contrarios [...] una democracia genuina en el sentido de un sistema político fundado en la noción del diálogo, la discusión, el debate, el disentimiento, el respeto por las minorías y por sus opiniones, y surgido de elecciones tar aquí la cuestión del disentimiento, legalmente protegido y fundamental para entender el concepto de democracia en las Antillas británicas.

Pero icómo se obtiene el consenso nacional cuando la práctica política parte del supuesto de que el derecho a disentir tiene prioridad sobre la necesidad del consenso mismo? La única respuesta posible se ubica en la práctica de la discusión y la participación, heredada de instituciones y representaciones sociales que, como se señalaba anteriormente, hicieron del intercambio de ideas y del en-

genuinamente libres donde los representantes particulares están sujetos a sanciones mediante el proceso electivo." Manley, Polttica, 1976, pp. 26-27. 
frentamiento político una facultad que se desarrollaba con relativa independencia de las estructuras de.dominación coloniales. En un sentido sociopolítico, Manley hace referencia al peso de la esclavitud en la vocación democrática de los jamaiquinos:

En el caso de Jamaica este temor [a la tiranía] es real y profundo y crea el clima fundamental para la actitud con la que el jamaiquino enfoca la cuestión de sus instituciones políticas. La esclavitud ha hecho del jamaiquino lo que la tiranía monárquica y religiosa hizo del norteamericano y lo que los señores feudales, la aristocracia terrateniente y finalmente los nuevos gobernantes empresariales de la revolución industrial hicieron en conjunto del inglés. 5

\section{LA RESPUESTA ORGANIZATIVA DE LOS PARTIDOS NACIONALES DE MASAS}

En la década previa a la segunda guerra mundial, el gobierno británico en las Antillas demostró poca visión política y social. Los retos que se le plantearon y que no encontraron solución, tales como la ampliación de la pobreza, la desaparición de barreras sociales y la oposición política de la aristocracia terrateniente, lo llevaron a la quiebra.

La respuesta al fracaso metropolitano provino de las organizaciones emanadas de la sociedad civil. En el momento de la independencia, la energía de los líderes partidarios se concentraba en dar respuesta a los apremiantes problemas socioeconómi-

\footnotetext{
S Manley, Política, 1976, pp. 30-31.
}

cos mencionados y en luchar por la independencia nacional. La urgencia del moniento obligó a crear estructuras autoritarias en las que las decisiones permanecían en manos de los comités centrales que "servían como instrumentos de transmisión de los de. seos del liderazgo". ${ }^{6}$ En esta coyuntura los líderes obreros más representativos fueron asimilados al proyecto metropolitano. Alejandro Bustamente en Jamaica, Grantley Adams y Eric Barrow en Barbados, Forbes Burnham en Gu. yana, Eric Gairy en Grenada son las figuras de este liderazgo que, junto con intelectuales como Norman Manley y Eric Williams de Trinidad, terminaron por servir a los fines de la corona.

A partir de entonces los partidos de masas ocupan el lugar del legislador colonial en la tarea de organizar la opinión pública. Lo significativo de este cambio es la remoción final de la Secretaría de Colonias, decisión que da por terminada la pretensión de poder gobernar todo un imperio desde una oficina londinense. Se inició así la transición del poder colonial a una burocracia representativa bajo control político local. ${ }^{7}$

Si bien es cierto que los problemas de desigualdad social y reparto inequitativo de la riqueza nacional son producto de deformaciones estructurales, no deja de ser menos cierto que el ingreso de la subregión a la modernidad neoliberal, experimentada bajo la Iniciativa de la Cuenca del Caribe de los años ochenta, ha acen-

6 Véase Singh, Local, p. 115.

7 Véase Lewis, Growth, 1968. 
tuado las tendencias históricas depresivas de las economías agrodependientes: dicho ingreso contribuyó exacerbar las tradicionales fricciones étnicosociales, las cuales, en un principio, fueron producto del régimen esclavista. Más tarde las enconó una integración social que incorporó al ex esclavo africano a una sociedad estratificada sin darle la oportunidad de una verdadera redención y enfrentándolo de manera abrupta a una competencia desigual con inmigrantes de otras nacionalidades que nunca fueron sometidos del todo a la explotación esclavista a que aquellos estaban sujetos.

Los acontecimientos de julio de 1990 en Trinidad Tobago pueden entenderse a la luz de los procesos arriba mencionados. En este sentido el in- tento de golpe de Estado, protagonizado por el Jamaat al Muslimeen, responde a una larga tradición de radicalismo étnico y racial en el Caribe no hispánico, y es característico de una democracia severamente teñida de influencias raciales y constituida alrededor de un pensamiento radical, el representado por Marcus Garvey a partir de los años treinta de nuestro siglo; este pensamiento se refleja en la revolución de febrero de 1970 en Trinidad Tobago y en Martinica y Guadalupe.

La ocupación del Parlamento trinitario, encabezada por el ex policía negro Yassim Abu Bakr, el incendio cle la estación de policía de Puerto Es paña y la toma de la estación de televisión, acciones ejecutadas simultánea mente, parecen responder en este marco a

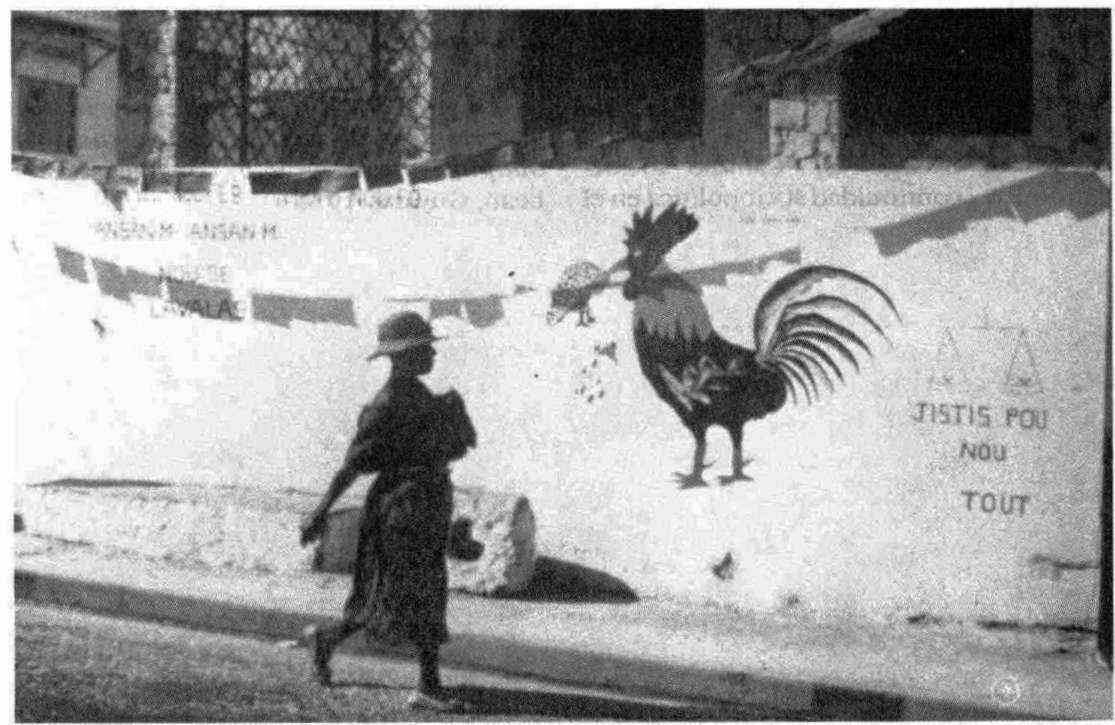


un plan preparado con antelación y confiado en una respuesta social amplia y de carácter popular pero, sobre todo, de una respuesta de identificación étnica.

\section{CONCLUSIÓN}

Las formas de organización política en las Antillas de habla inglesa, tienen como núcleo los gobiernos locales y un vigoroso desarrollo comunitario. El grupo representante de los intereses de los plantadores que en el pasado amenazó la autonomía local, se opuso también a que se avanzara en el camino de la democracia social y económica. No obstante, las diferencias étnicas y los enfrentamientos emanados de las mismas siguen siendo las barreras más difíciles de superar en el camino de la democracia subregional.

\section{Bibliografía}

-Beckford, George, L., "Cambio socioeconómico y continuidad sociopolítica en el
Caribe anglófono, un esbozo", en Gérard Pierre Charles (comp.), Relaciones internacionales y estructuras sociopolíticas en el Caribe, México, UNAM, 1980.

-Giacalone de Romero, Rita, "El Estado democrático-clientelista en Trinidad y Tobago", El Caribe Contemporáneo, núm. 14, junio 1987, pp. 23-25.

-Hume, Wrong, Government of the West Indies, Oxford, 1923.

-Lampe, Armando, "Problemas de la democracia en el Caribe holandés: el caso de Bonaire," El Caribe Contemporáneo, núm. 22, enero-julio 1991, pp. 81-91.

-Lewis, Gordon, The growth of the modern West Indies, Modern Reader's Paperbacks, Nueva York, 1976.

-Pierre Charles, Gérard, "Conceptos sobre el Estado en las sociedades del Caribe", en Pablo González Casanova (comp.), El Estado en América Latina. Teoria y práctica, Siglo XXI Editores, México, 1990.

-Serbín, Andrés, "Trinidad: un arcoiris racial fragmentado. La crisis política y social interna", El Caribe Contemporáneo, núm. 21, Julio-diciembre 1990, pp. 7-14.

-Singh, Paul, Local democracy in the Commonwealtb caribbean. A study of adaptation and growth, Longman Caribbean, Guyana, 1972. 